\title{
OPINION
}

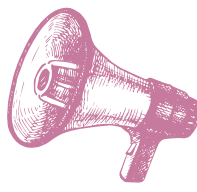

\section{A National Mathematics Festival and a Movement}

David Eisenbud and Kirsten Bohl

\section{Note: The opinions expressed here are not necessarily those of Notices.}

Responses on the Notices webpage are invited.

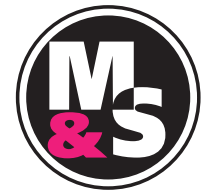

We write this in the last days of 2016, an unsettling and divisive year on many fronts. There's one continuing trend that readers of this column will probably all agree is good: the remarkable increase in public attention paid to mathematics.

By the time you read this, the cherries will be blooming in Washington, DC, where more than thirty thousand children and adults will gather on April 22 at the Washington Convention Center for a day of lectures, puzzles, games, mathletic events, art-making, and performances-that's right, for the second National Math Festival, organized by MSRI in cooperation with the Mathematical Sciences Research Institute in Berkeley in cooperation with the Institute for Advanced Study in Princeton, with MoMath, the National Museum of Mathematics.

We are struck by how different the national backdrop is from the first time in 2015. More and more, our math and science organizations are taking lead roles in encouraging the public to take joy in, understand more deeply, and perhaps feel a deeper and more positive personal connection with mathematics. It would be hard to make a systematic list of all that's happening-that's certainly beyond our capacity and beyond the space for this essay! But here are a few morsels:

David Eisenbud and Kirsten Bohl are director and outreach producer, respectively, at the Mathematical Sciences Research Institute. Their e-mail addresses are de@msri.org and kboh1@ msri.org.

For permission to reprint this article, please contact: reprint-permission@ams . org.

DOI: http://dx.doi.org/10.1090/noti1501
- the weekly "Varsity Math" puzzle column by MoMath in the Wall Street Journal;

- the proliferation of math festivals around the world, including in Mexico City and Rio de Janeiro;

- the creation of Math Outreach International (born in Banff) and the likewise international MATRIX and MOVES conferences;

- the declaration of Global Math Week October 10-17, 2017, and its ambition to make short, engaging math videos entirely visual to obviate the trickiness of language differences;

- the expansion of Bob Moses's Algebra Project and the Flagway Game from their firm successes in inner cities of the United States to small villages in the Irish countryside;

- Math Circles reaching a national spotlight informed about in The Atlantic magazine;

the good things • the nearly two-million-strong Numberphile YouTube channel, which has occasioned we notice. Circles movie; many, many self-reports of turnarounds in feelings about math (and maths);

- the awards accruing to the Navajo Math

- the nascent Mathical Book Prize for young children to teens;

- the international IMAGINARY mathematics exhibitions, described in the previous Notices article, page 368.

It's a heady world these days and one that's different from that of 2015.

As we write this, Francis Su has just launched his MathFeed app, aggregating news, social media, puzzle columns, book reviews, and more about mathematics, 
math education, and related fields. As more of the rising tide of information around us begins to celebrate mathematics in myriad and surprising ways, let's keep one another informed about the good things we notice. At MSRI we will keep developing the More Math! section of the Nationa1MathFestiva1.org website, where we are curating recreational math resources year-round. What will 2017 bring? It's safe to wager we can expect more good news!

When April comes around each year, let's make an even bigger splash with Math Awareness Month. The public understanding of math serves us all, and we are pleased and proud to be shoulder to shoulder with the AMS, AWM, NAM, MAA, SACNAS, and SIAM* to kick up a mathy fuss in fresh and interesting ways. With the Association of Science-Technology Centers, this year MSRI will host Giant SOMA Cube workshops at many dozens of science museums around the country as an extension of the National Math Festival.

If we keep to the trend, the next National Math Festival after this April will be in 2019. We can only guess what the world might be saying and doing and feeling and thinking about mathematics by then, but we do know we want to be in the company of others of goodwill, excitement, and a growth mindset to find out.

*Association for Women in Mathematics, National Association of Mathematicians, Mathematical Association of America, Society for Advancement of Chicanos/Hispanics and Native Americans in Science, Society for Industrial and Applied Mathematics.

\section{Photo Credits}

Photos of David Eisenbud and Kirsten Bohl are courtesy of Cliff Stoll.

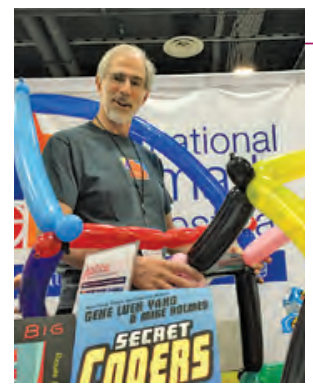

\section{ABOUT THE AUTHORS}

David Eisenbud loves mathematical fun of all kinds-from core research to balloons - and is delighted to see many nonmathematicians reacting in the same way when they get the chance.

\section{David Eisenbud}

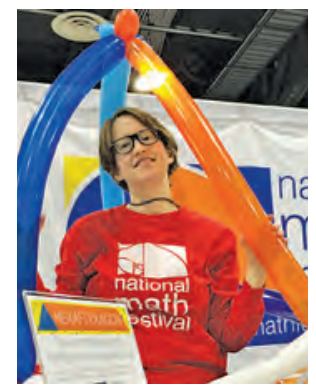

Kirsten Bohl is happiest in her work at MSRI when surrounded by balloons, children, and mathematics - not necessarily in that order.

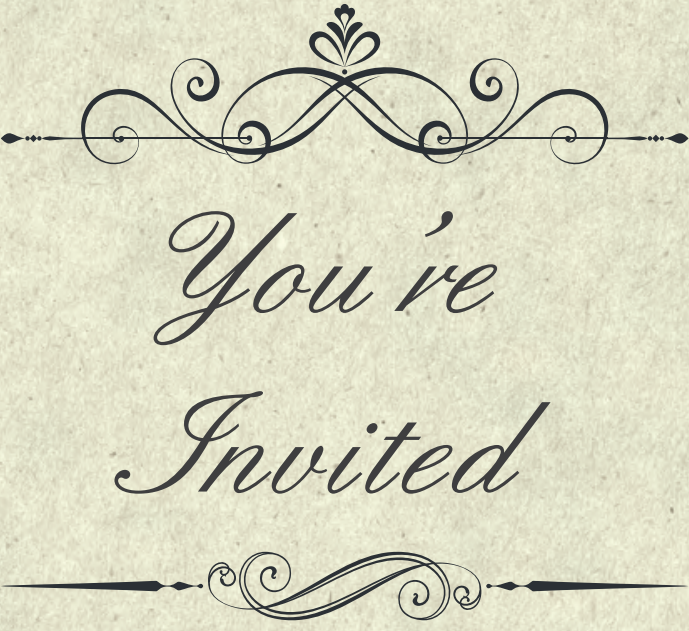

The Editor-in-Chief invites all

readers, from students to retired

folks, to get more involved with

Notices as authors, editors, guest

editors, writers of Letters

to the Editor, and so on.

E-mail your interests, ideas, or nominations of others to

Frank.Morgan@williams.edu.
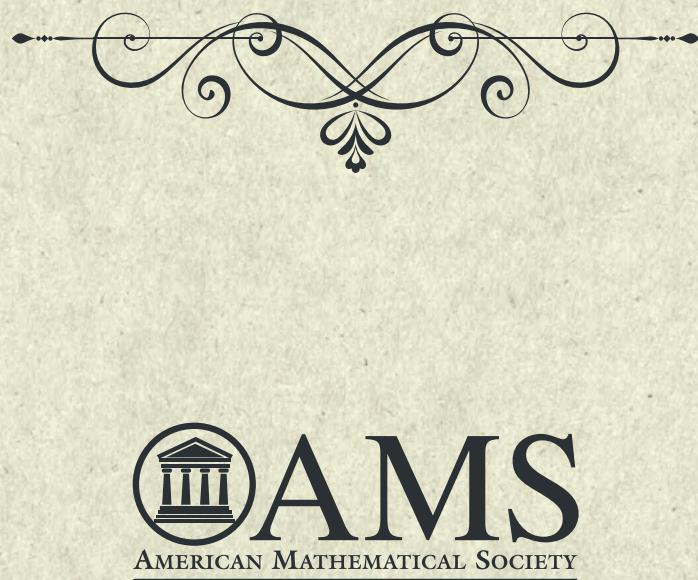

Www.ams.org 